\title{
Influence of some ecological factors on the filtration intensity of the oyster (ostrea edulis I.)
}

\author{
Natalya Sytnik $^{1, *}$ \\ ${ }^{1}$ Kerch State Maritime Technological University, 298309, Kerch, Ordzonikidze str. 82, the Crimea, \\ Russia
}

\begin{abstract}
The quantitative regularities of filtration of the Black Sea oyster are studied depending on a number of environmental factors. The influence of food concentration on the filtration activity of mollusks is considered. The dependences of the filtration rate on the body weight of oysters for different temperature regimes were determined, and seasonal changes in its intensity in the Kerch Strait and the Donuzlav estuary were characterized. The influence of water salinity on the filtration activity of this type of mollusks has been established.
\end{abstract}

\section{Introduction}

Flat (ridge, European) oyster - Ostrea edulis L. is one of the most valuable representatives of the Black Sea malacofauna [1-4]. At the beginning of the last century, populations of this species were widespread along the entire coast of the Black Sea basin, but then the number and range of oysters began to steadily decline $[2,7]$. In the $60 \mathrm{~s}$ and $70 \mathrm{~s}$ of the 20 th century, for various reasons, there was a massive degradation of natural settlements of the Black Sea oyster $[2,3,5,7]$. At present, this species is represented in the Black Sea only by individual micropopulations. In this regard, the need arose for the artificial reproduction of this species [1-4], which is possible only on the basis of detailed studies of various aspects of the life of this species.

Nowadays, work on the mariculture of the flat oyster in the Black Sea is mainly associated with the early stages of ontogenesis - the mass production of larvae spat of this species in artificial conditions $[3,4]$. At the same time, the number of studies devoted to the late stages of ontogenesis is insignificant [2, 8]. In particular, this concerns such an important area as the study of the regularities of filtration nutrition and nutritional needs of a given species. Currently, there are many publications on this issue in the world literature $[8,10-15]$, while the number of domestic works on the nutrition of the Black Sea oysters is insignificant $[2,9]$.

Meanwhile, these studies are not only of practical importance, for example, for calculating the optimal density in the process of rearing spat, during the formation of brood stock and the development of biotechnology for artificial reproduction in general, but also have a certain theoretical interest for comparative and evolutionary ecology and physiology.

\footnotetext{
*Corresponding author: sergiiblack@gmail.com
} 
The purpose of this work is to characterize the influence of a number of environmental factors (concentration of food, temperature, water salinity) on the intensity of filtration nutrition of the Black Sea oyster.

\section{Materials and methods}

The work was carried out in 2004-2006 in the Kerch Strait and the Donuzlav estuary (western coast of Crimea). The material for the study was individuals of different sizes, 26$81 \mathrm{~mm}$ in height and 0.4-73.9 $\mathrm{g}$ in weight (with shell).

Mollusks collected from fouling and collectors were kept in aquariums with water temperatures consistent with the environment. After the catch, the oysters were kept in aquariums for 24 hours in order to free their gastrointestinal tract from the contents. The unicellular alga Skeletonema sp. was used as food (1 million cells - $1.2 \mathrm{mg}$ in wet weight).

The experiments were carried out in vessels with a volume of 3-12 liters, depending on the size and number of individuals in the experiment. To select a method for calculating the filtration rate (FR), 3-4 hour experiments on the intensity of algae consumption by mollusks were carried out. It was found that the decrease in the concentration of feed in the studied vessels was properly described by the exponential equation:

$$
K t=K o \cdot e-p \cdot t
$$

where Ko and Kt - the initial and final concentration (mg.l-1) of the suspension per hour, respectively, $\rho$ - the specific rate of decrease in the concentration (h-1), which in the experiments was equal to $0.223-0.344$. In this regard, the filtration rate of oysters was determined by the Gold formula $[12,15,17]$ :

$$
F=\frac{\ln K_{o}-\ln K_{t}}{n \cdot t} \cdot V
$$

where $\mathrm{F}$ - filtration rate $(\mathrm{l} \cdot \mathrm{h}-1), \mathrm{K} 0$ and $\mathrm{Kt}$ - suspension concentration at the beginning and end of the experiment (mg-1-1), V - volume of water in the test vessel (l), $\mathrm{t}$ - duration of the experiment (hour), $\mathrm{n}$ - the number of mollusks in the experiment, $\mathrm{ln}$ - natural logarithm.

The initial density of algae was determined immediately before the experiment by direct counting in a Fox-Rosenthal chamber. After the end of the experiment, in order to avoid errors in the calculation, the remaining algae were concentrated using a back filtration funnel, after which their density was determined. The rate of nonbiological sedimentation of algae was defined by determining their concentration in control vessels for the same period of time as in the experiment.

When analyzing the data obtained, we used the results of experiments where the concentration of algae decreased by no more than $25 \%$ of the initial density of the suspension, since to this value, the decrease in concentration over time corresponded to an exponential equation. The duration of the experiments varied within 2-4 hours, depending on the volume of the vessels and the size of the mollusks.

The study of the effect of different concentrations of phytoplankton on FR and the volume of the diet of mollusks was carried out on two size groups: 33-35 and 53-57 mm. The experiments were carried out so that they corresponded to the temperature of the animals' environment. Depending on the season of the year, the water temperature in the experiments varied within the range of $10-27^{\circ} \mathrm{C}$. Salinity in the Donuzlav estuary varied from 17.2 to $18.1 \%$ (average - $17.7 \%$ ), in the Kerch Strait it was within 13.8-14.5 \%o (average - $14.2 \%$ ). 
After the end of the experiment, the mollusks were subjected to biological analysis (the length of the animal, the total weight, the mass of soft tissues, sex, and the stage of maturity were determined). To determine the dry mass of soft tissue, it was separated from the valves and dried to constant weight at a temperature of $70^{\circ} \mathrm{C}$ for 3 days [17].

Statistical processing of the data obtained was carried out using the Statistica computer program, Microcal Origin 6.1 and Excel electronic tables.

Research results and their discussion. The study of filtration activity showed that in oysters of the size group 33-35 $\mathrm{mm}(\mathrm{W}=2.5-3.6 \mathrm{~g})$, when exposed to algae in a wide range of concentrations (1.1 - 12.1 mg.1-1), noticeable changes of FR occur (fig. 1)

At low values of density of algal flora $(0.2 \mathrm{mg} \cdot 1-1)$, the FR of oysters was relatively small and amounted to 0.461 year-1. With an increase in food concentration up to $1.2 \mathrm{mg} \cdot 1$ 1 , FR significantly increases and becomes equal to 0.921 year- 1 . With an increase in the density of algae to $2.3 \mathrm{mg} \cdot 1-1$, a slight decrease in FR was observed - to $0.7 \mathrm{l} \cdot \mathrm{h}-1$. However, a further increase in the concentration of algae leads to a persistent decrease in the filtration activity of mollusks. The dependence of FR on food concentration for this size group of mollusks is satisfactorily approximated by the equation:

$$
F=1.04 \cdot \mathrm{Ko}-0.52 \pm 0.051, r=0.95
$$

where F - filtration rate (1·year-1), Ko - initial concentration of algal flora (mg-1-1), $\mathrm{r}$ correlation coefficient.

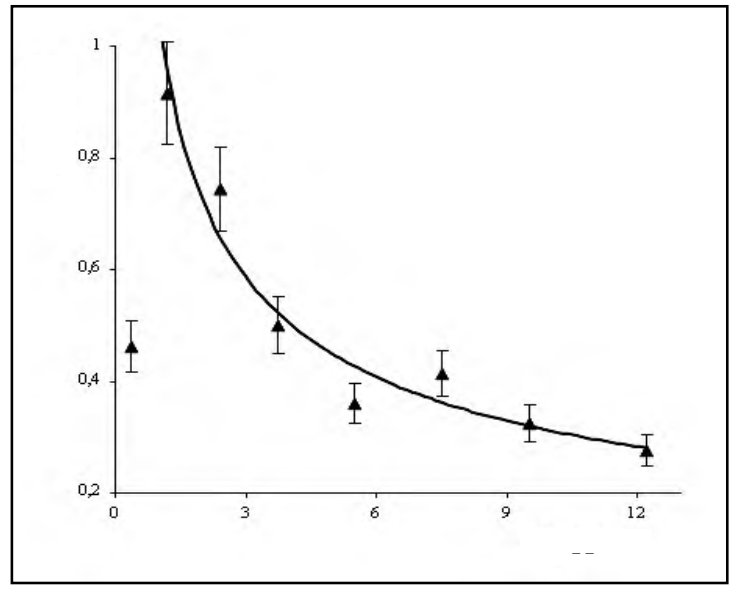

Fig. 1. Dependence of the filtration rate (F, 1.year-1) of oysters (33-35 mm height) on the phytoplankton concentration (K, mg-1-1). Vertical lines - 95\% confidence interval.

A similar nature of FR changes depending on food concentration was also observed in larger oysters, $53-57 \mathrm{~mm}$ in size $(\mathrm{W}=15.8-17.2 \mathrm{~g})$. For individuals of this group, the relationship between these variables was:

$$
F=2.47 \cdot \mathrm{Ko}-0.95 \pm 0.116, r=0.97
$$

Thus, the dependence of FR on the density of algae in different size groups of oysters is characterized by a single dependence, differing only in the quantitative values of the parameters.

The data obtained indicate that oysters can regulate FR depending on the concentration of food particles, which is confirmed by previously obtained data on other species of marine bivalves [15-18]. As for the data on the low filtration rate of oysters at low suspension concentrations, it can be assumed that this is, perhaps, due to the lower 
efficiency of algae capture by the hydrokinetic apparatus of mollusks. Therefore, the calculated FR is somewhat understated $[17,19]$.

The study of the FR of oysters depending on body weight in the studied areas showed that, as in other species of bivalve mollusks [10, 16-18], these indicators are closely related and are well approximated by a power function:

$$
F=F 1 \cdot W n
$$

where F - filtration rate, 1.year-1; W - dry body weight (without shell), g; F1 proportionality coefficient numerically equal to the filtration rate at $\mathrm{W}$ equal to $1 \mathrm{~g} ; \mathrm{n}$ regression coefficient, the value of which characterizes the specific filtration rate of oysters with a change in body weight.

In a double logarithmic coordinate system, the dependence of the filtration rate on body weight is expressed by a straight line with a certain angle of inclination (Fig. 2).

Experiments carried out in the areas of the Kerch Strait and the Donuzlav estuary in different seasons of the year and, accordingly, at different temperatures and salinity of water showed significant changes in the filtration rate (Table 1).

Analysis of the data obtained on the filtration activity of the Black Sea oyster showed that they are in good agreement with the works of other authors on this species. Thus, in Rodhouse's article [14], the dependence of FR on dry ash-free body mass at 200C was described by the equation:

$$
F=1.63 \cdot W 0.477
$$

Since the mineral fraction is about $10 \%$ of the dry body weight of oysters, the materials obtained by this author are close to our data [14].

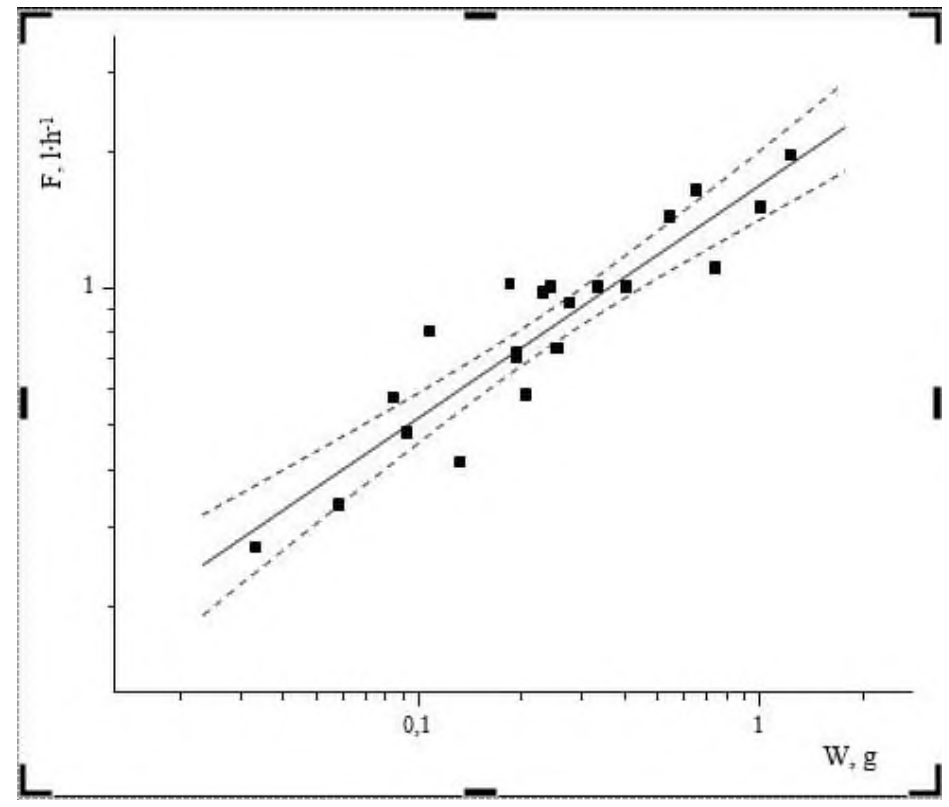

Fig. 2. Dependence of filtration rate $(\mathrm{F}, \mathrm{l} \cdot \mathrm{h}-1)$ on dry body mass (W, g) of oysters (Donuzlav estuary ( $\mathrm{T}=160 \mathrm{C}, \mathrm{S}=17.6 \%$, dashed lines $-95 \%$ confidence interval).

Similar data are presented in the article by Haure et al. [11], who studied the filtration rate in the temperature range $10-300 \mathrm{C}$ and found the maximum value of $\mathrm{F} 1$ equal to 3.188 $1 \cdot$ year- $1 \cdot h-1$, but at a temperature of $300 \mathrm{C}$. Data close to ours are given in the work of 
Shumway et al. [16]. The authors have shown that in Ostrea edulis L., the filtration rate is $1594 \mathrm{ml} \cdot y e a r-1$ at $120 \mathrm{C}$. We can also note the work of Winter et al. [18], where the researchers, studying the closely related species Ostrea chilensis, found that at a temperature of $13.50 \mathrm{C}$ and a salinity of $23.6 \%$, the relationship between FR and dry body weight was expressed by the allometric equation, the proportionality and regression coefficients of which were 1.32 and 0.63 , respectively, which is comparable with the materials we obtained.

\section{Results}

The lowest activity (coefficient F1) of filtration of mollusks was observed in the Kerch Strait at 70C; with an increase in water temperature, its value steadily increased. The coefficient of proportionality (F1) of mollusks reached its maximum value at $23^{\circ} \mathrm{C}$; with a further increase in temperature to $27^{\circ} \mathrm{C}$, the values of both the coefficient of proportionality and regression decreased.

Table 1. Parameters of the equation of the relationship between the filtration rate (F, l.h-1) with dry body weight $(\mathrm{W}, \mathrm{g})$ of oysters in the Kerch Strait $(\mathrm{S}=13.8-14.5 \%$ ) and the Donuzlav estuary $(\mathrm{S}=$ $17.2-18.1 \%)$. *

\begin{tabular}{|l|c|c|c|c|c|c|c|}
\hline $\begin{array}{l}\text { Work period } \\
\left(\mathrm{T}^{\mathrm{O}} \mathrm{C}\right)\end{array}$ & $N$ & $W$ & $F_{I}$ & $S_{r}$ & $n$ & $S_{n}$ & $r$ \\
\hline \multicolumn{7}{|c|}{ Kerch Strait } \\
\hline December (7) & 18 & $0.017-0.93$ & 0.54 & 0.079 & 0.443 & 0.138 & 0.797 \\
\hline April (13) & 21 & $0.027-0.97$ & 1.20 & 0.214 & 0.583 & 0.108 & 0.836 \\
\hline June (20) & 19 & $0.044-1.14$ & 2.05 & 0.198 & 0.602 & 0.091 & 0.851 \\
\hline \multicolumn{7}{|c|}{ Donuzlav estuary } \\
\hline November (10) & 19 & $0.022-1.02$ & 0.88 & 0.059 & 0.435 & 0.044 & 0.883 \\
\hline May (16) & 23 & $0.033-1.23$ & 1.69 & 0.203 & 0.512 & 0.049 & 0.918 \\
\hline July (23) & 23 & $0.024-1.08$ & 2.37 & 0.268 & 0.487 & 0.074 & 0.891 \\
\hline August (27) & 20 & $0.025-1.29$ & 1.97 & 0.201 & 0.606 & 0.115 & 0.856 \\
\hline
\end{tabular}

Note: ${ }^{*} \mathrm{~N}$ - number of mollusks in the experiment, $\mathrm{W}$ - limit values of dry mass of mollusks in the experiment, $\mathrm{Sr}$ - standard error F1, Sn - standard error n; r - correlation coefficient.

Experiments in the Kerch Strait and Donuzlav estuary were carried out at different values of temperature and salinity of water, and this led to different values of the proportionality and regression coefficients of the obtained equations. This, in turn, does not allow an accurate comparison of the available data. For their strict comparison, two ways are used $[10,13,17]$ - the adoption of one, the most probable value of the regression coefficient, followed by the transformation of materials and finding F1 for each series of research data, or comparison of the filtration rate $(\mathrm{F} / \mathrm{W})$ in animals of the same weight.

We used the 2nd variant of the calculation. For this, the geometric mean values of the mollusks mass for each row were determined. Their values in different variational series varied within 0.231-0.277 g. Based on these data, the geometric mean value of the mass was taken to be $0.255 \mathrm{~g}$, after which $\mathrm{F} / \mathrm{W}$ was found for each experimental series. The results of the comparative analysis were ranked in order of increasing water temperature separately for each region (Fig. 3).

The analysis showed that in the studied areas, in parallel with the change in water temperature, there is a significant change in the $\mathrm{F} / \mathrm{W}$ values. A well-pronounced tendency is 
observed - with an increase in water temperature, the filtration intensity of mollusks increases, which reaches a maximum at a temperature close to $230 \mathrm{C}$ (Fig. 3).

A further increase in temperature to $270 \mathrm{C}$ leads to a decrease in the intensity of filtration.

It is known that the value of the temperature optimum favorable for the vital activity of this oyster species depends on the biotope conditions and can vary within the range of 22$300 \mathrm{C}[10,11,13]$. Due to the fact that in the Black Sea this species lives at the edge of its range, some of its shift in the optimum of filtration activity towards low temperatures is, perhaps, caused by the adaptation of oysters to lower values.

In connection with the data obtained, it was of interest to assess the value of the Van't Hoff temperature coefficient - Q10, which indicates an increase in the rate of metabolic processes with an increase in temperature by $100 \mathrm{C}$. In the Kerch Strait, with an increase in water temperature from 7 to $130 \mathrm{C}$, the value of the coefficient Q10 was 2.66, while with an increase from 13 to $200 \mathrm{C}$, its value was much less -2.07 .

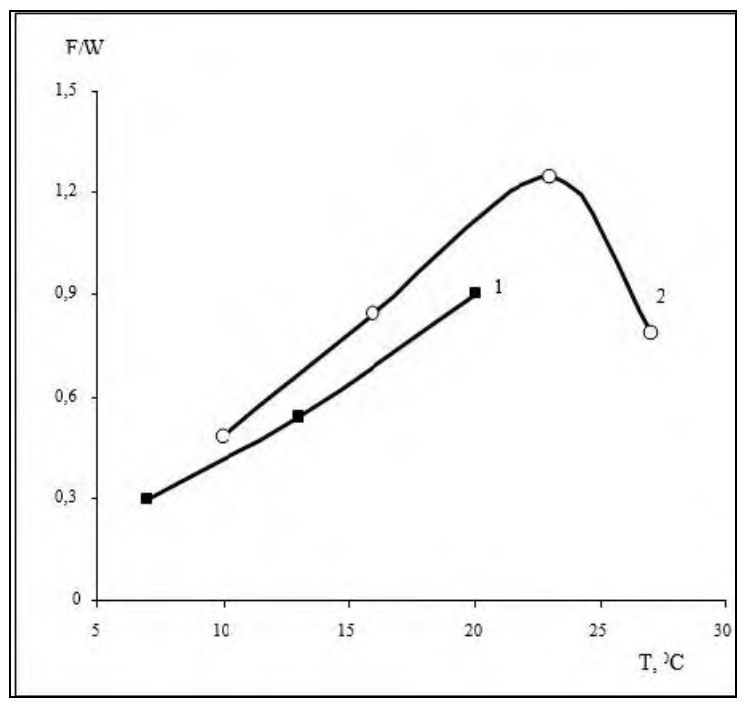

Fig. 3. Change in the filtration intensity $(\mathrm{F} / \mathrm{W})$ of oysters depending on the water temperature in the Kerch Strait (1) and the Donuzlav estuary (2).

In the Donuzlav estuary, in the range $10-160 \mathrm{C}$, the value of Q10 was 2.57 , whereas with an increase in temperature from 16 to $230 \mathrm{C}$, the value of Q10 decreased to 1.75 . A further increase in temperature up to $270 \mathrm{C}$ led to a sharp decrease in Q10 to 0.40 .

The data obtained indicate that the dependence of the filtration rate of oysters on temperature was close to the value of 2.25 proposed by G.G. Vinberg [17]. It is noteworthy that at low values of water temperature, its change by the same value is affecting the filtration intensity to a greater extent than at higher ones. It is possible that this is due not only to temperature, but also to the different physiological state of the mollusks, in particular, their reproductive activity [6,19].

The upper boundary of the biokinetic zone of the Black Sea oysters is the temperature close to $230 \mathrm{C}$, above which the physiological processes of the studied animals decreased markedly. At the same time, the Q10 value is close and less than 2, indicating the possibility of partial compensatory changes in the filtration intensity.

The studies carried out also indicate that under conditions of low salinity of the Kerch Strait waters (13.8-14.5\%), the intensity of oyster filtration was noticeably lower than in the Donuzlav estuary (Fig. 3). 
We compared F/W in the indicated water areas as follows. For oysters in the Donuzlav estuary, the dependence on water temperature was approximated by an exponential function, which in numerical form had the following form:

$$
F / W=0.236 \cdot e 0.075 \cdot T,
$$

On the basis of this equation, the theoretical values of $\mathrm{F} / \mathrm{W}(0.255)$ were calculated at temperatures of 7, 13 and $200 \mathrm{C}$, respectively, i.e. at which experiments were carried out in the Kerch Strait.

The analysis showed that at the same temperature, but in water of different salinity, the F/W value in the Donuzlav estuary is $15.8-33.0 \%$ higher than in the Kerch Strait. Thus, with a decrease in salinity by $3.5 \%$, the filtration intensity of oysters decreases on average by $22.1 \%$. This is confirmed by previously obtained data on the effect of salinity on the vital activity of this species of mollusks $[5,12,15]$.

\section{Conclusions}

1. The highest filtration activity in oysters is observed at a food concentration of 1.2-2.3 $\mathrm{mg} \cdot 1-1$. With its growth to $12.2 \mathrm{mg} \cdot 1-1$, the filtration rate in mollusks steadily decreases.

2. With an increase in water temperature, the intensity of filtration of the Black Sea oyster increases, reaching a maximum at $230 \mathrm{C}$; its further increase leads to a decrease in the filtration activity of mollusks.

3. The intensity of filtration of oysters depends on the salinity of the water - when it decreases by $3.5 \%$, the filtration activity of mollusks decreases on average by $22.1 \%$.

\section{References}

1. A.P. Zolotnitsky, A.N. Orlenko, V.G. Kryuchkov, N. A. Sytnik, On the organization of large-scale cultivation of oysters in Lake Donuzlav, Proceedings of YugNIRO 46, 4854 (2008)

2. T.F. Karakatitsa, Biology of the Black Sea oyster in connection with the issues of its reproduction, Biological bases of marine aquaculture 2, 79 (1976)

3. V.L. Monin, Biological bases of cultivation of the Black Sea oyster Ostrea edulis L. (1990)

4. A.V. Pirkova, L.V. Ladygina, V. I. Kholodov, Reproduction of the Black Sea oyster Ostrea edulis L. as an endangered species, Fish industry of Ukraine 3-4, 8-12 (2002)

5. T.F. Karakatitsa, Reduction of the range and decrease in the number of oysters in the Egorlytsky Bay, Mollusks, The main results of their study 112-114 (1979)

6. S. Sokolov, A. Zhilenkov, S. Chernyi, A. Nyrkov, D. Mamunts, Dynamics Models of Synchronized Piecewise Linear Discrete Chaotic Systems of High Order, Symmetry 11(2), 236 (2019) doi: 10.3390/sym11020236

7. M.V. Pereladov, The current state of the population of the Black Sea oyster, Coastal hydrobiological research, Proceedings of VNIRO 144, 254-274 (2005)

8. A.V. Suprunovich, Yu.N. Makarov, Cultivated invertebrates (1990)

9. A.P. Zolotnitskiy, Kruk L.S. Study of filtration nutrition of the Black Sea oyster (Ostrea edulis L.), Tes. report of the III congress of oceanol 2, 23-30 (1987) 
10. C.D. Buxton, B.C. Newell, J. G. Field, Response surface analysis of the combined effects of exposure and acclimation temperatures on filtration, oxygen consumption and scope for growth in the oyster Ostrea edulis, Mar. Ecol. Prog. 6, 73-82 (1981)

11. J. Haure, C. Penisson, S. Bougrier, J.P. Baud, Influence of temperature on clearance and oxygen consumption rates of the flat oyster Ostrea edulis: determination of allometric coefficients, Aquaculture 169, 211-224 (1998)

12. S. Hutchison, L.E. Hawkins, Quantification of the physiological responses of the European flat oyster Ostrea edulis L. to temperature and salinity, J. Moll. Stud. 58, 215-226 (1992)

13. K.C. Newell, L.G. Johnson, L. H. Kofoed, Adjustment of the components of energy balance in response to temperature change in Ostrea edulis, 0ecologia (Berl.) 7, 30, 97-110 (1981)

14. P.G. Rodhouse, Energy transformations by the oyster Ostrea edulis L. in a temperature estuary, J. exp. mar. Biol. Ecol. 34,1, 1-22 (1978)

15. E.M. Roedstroem, Survival and feeding activity of oyster spat (Ostrea edulis L.) as a function of temperature and salinity with implications for culture policies on the Swedish west coast, J. Shellfish Res. 19, 2, 799-808 (2000)

16. S.E. Shumway, T.L. Cucci, K.C. Newell, C.M. Yentsch, Particle selection, inception and absorption filter-feeding bivalves, J. Exp. Mar. Biol. 91, 5, 77-92 (1985)

17. A.F. Alimov, Functional ecology of freshwater bivalve mollusks (L.: Nauka, 248, 1981)

18. J.E. Winter, M.A. Acevedo, J. H. Navarro, Quempillen estuary, an experimental oyster cultivation station in southern chili, energy balance in Ostrea chilensis, Mar. Ecol. Prog. Ser. 20, 151-164 (1984)

19. A. Nyrkov, A. Zhilenkov, S. Sokolov, S. Chernyi, Hard-and Software Implementation of Emergency Prevention System for Maritime Transport, Automation And Remote Control 79(1), 195-202 (2018) doi: 10.1134/s0005117918010174 